\title{
A ESPACIALIZAÇÃO DA EXPANSÃO DA REDE FEDERAL DE EDUCAÇÃO PROFISSIONAL, CIENTÍFICA, E TECNOLÓGICA NO ESTADO DO PARANÁ
}

Jesué Graciliano da Silva* Frederico Fonseca da Silva**

RESUMO: O Plano de Expansão da Rede Federal de Educação Profissional, Científica e Tecnológica (RFEPCT) completou em 2015 uma década. Desde 2005, quando foi realizado o lançamento do programa de expansão da RFEPCT, foram construídos mais de 400 novos campi em todo o país, que se somaram aos 152 existentes. O artigo tem por objetivo descrever como ocorreu a espacialização da expansão da RFEPCT no Estado do Paraná no período de 2005 e 2015, onde a rede passou de oito para 37 campi. Para tanto, realizou-se o levantamento dos indicadores socioeconômicos e da posição de cada uma das cidades atendidas pela RFEPCT nas fases da pré-expansão e da expansão por meio do Software livre Quantum GIS - Sistema de Informação Geográfica e dados oficiais do IBGE. Foi possível identificar onde houve maior grau de interiorização e de percentual de população atendida, bem como identificar quais as regiões que são mais deficitárias em relação à oferta de matrículas na RFEPCT. Essas informações são importantes para o planejamento de futuros novos campi da RFEPCT e para se compreender de que forma eles podem contribuir efetivamente para o desenvolvimento regional do Paraná.

PALAVRAS-CHAVE: Desenvolvimento; Educação profissional; Expansão.

\section{THE EXPANSION OF THE FEDERAL PROFESSIONAL, SCIENTIFIC AND TECHNOLOGICAL EDUCATION NET WORK IN THE STATE OF PARANÁ, BRAZIL}

ABSTRACT: Ten years have elapsed since the establishment of the Expansion Plan of the Federal Professional, Scientific and Technological Education Network (RFEPCT) in 2015. Since the launching of the RFEPCT expansion in 2005, more than 400 new campuses were established throughout Brazil, coupled to the 152 already in activity. Current paper describes the manner spatialization of RFEPCT expansion occurred in the state of Paraná, Brazil, between 2005 and 2015, when network rose from

Doutor em Geografia. Instituto Federal de Santa Catarina (IFSC), Brasil. E-mail: jesuegraci@gmail.com

* Engenheiro agrônomo; Doutor em Irrigação e Meio Ambiente; Docente e Pesquisador do Instituto Federal do Paraná (IFPR), Curitiba (PR), Brasil. 
8 to 37 campuses. A survey was undertaken on the socioeconomic indicators and their position in each city attended by the RFEPCT during the pre-expansion and expansion phases by using Quantum GIS (Geographic Information System) and official IBGE data. Greater degree in interiorization, population percentage, and more deficit regions with the regard to enrolment was identified. Data are highly relevant for future RFEPCT campuses and the way they may contribute towards the effective development of the state.

KEY WORDS: Development; Professional education; Expansion.

\section{INTRODUÇÃO}

$\mathrm{O}$ artigo se propõe a descrever e avaliar o processo de expansão da Rede Federal de Educação Profissional, Científica e Tecnológica (RFEPCT) no Estado do Paraná. Este tema se justifica por sua contribuição para melhoria do planejamento e ordenamento de políticas públicas educacionais, em nível municipal, estadual e nacional. A metodologia para elaboração da pesquisa envolveu a realização de revisão bibliográfica, análise de relatórios de gestão dos Institutos Federais e do Ministério da Educação, aplicação de questionários e realização de entrevistas com autoridades. Também foram comparados os dados socioeconômicos dos municípios atendidos pela RFEPCT na pré-expansão e na expansão a partir das estatísticas disponibilizadas pelo IBGE. Por isso a pesquisa pode ser classificada como quantitativa e qualitativa.

Antes de descrever o processo de expansão da RFEPCT é importante ressaltar que as primeiras escolas profissionalizantes federais foram implantadas no ano de 1909, com a publicação do Decreto $n^{0} 7.566$, do presidente Nilo Procópio Peçanha, que criou 19 Escolas de Aprendizes e Artífices (BRASIL, 1909). Na Figura 1, tem-se a espacialização das Escolas de Aprendizes Artífices em 1909. 


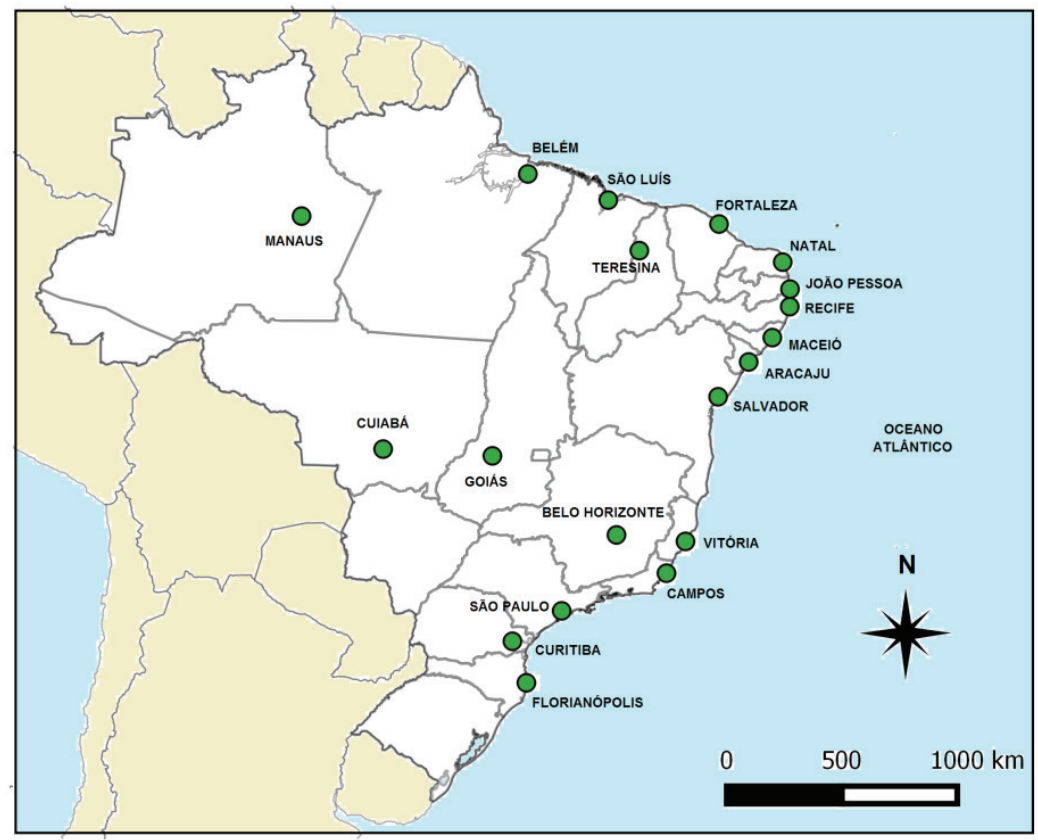

Figura 1. Distribuição das primeiras 19 Escolas de Aprendizes Artífices. Fonte: Elaboração própria a partir de BRASIL (1909) e PEIXOTO³ (2008).

Os Estados do Rio Grande do Sul e Acre não foram contemplados. O Acre havia sido incorporado ao território nacional alguns anos antes. O Rio de Janeiro foi contemplado, mas a escola foi construída no município de Campos.

Essas escolas surgiram duas décadas após a proclamação da República Brasileira e eram destinadas preferencialmente aos "desfavorecidos da fortuna". Esse foi um período de grandes transformações sociais, culturais e econômicas decorrentes do fim da escravatura, da consolidação do processo de imigração e da expansão da economia cafeeira, que possibilitou investimentos na infraestrutura das ferrovias, estradas e indústrias. Nesse período, a formação para o trabalho foi um expediente utilizado como meio de contenção daquilo que se chamava de "desordem social". O caráter assistencialista da educação profissional começou a ser superado na década de 1950, na gestão do presidente Juscelino Kubitschek (19561961), quando foram realizados grandes investimentos em infraestrutura por meio

3 O mapa do Brasil de 1909 foi baseado na ilustração disponibilizada no e-book de Afrânio Peixoto (2008), disponivel em: http://www.ebooksbra sil.org/eLibris/peixoto.html 
do Plano de Metas. O Plano de Metas era um conjunto de 30 objetivos definidos pelo governo para alavancar diversos setores da economia como energia e transportes. Nesse contexto, houve uma intensificação da formação de profissionais técnicos, indispensáveis ao processo de industrialização.

O surgimento dos primeiros CEFETs - Centros Federais de Educação Tecnológica, em 1978 é coincidente com o período designado por Milton Santos (2012) como "técnico-científico-informacional", no qual o "toyotismo", também conhecido como "modo de produção flexível", tornou-se importante, exigindo maior grau de qualificação dos trabalhadores.

A década de 90 teve início com o Governo do Presidente Fernando Collor de Mello e com a adoção do ideário neoliberal e a Política do Estado Mínimo, seguindo os princípios emanados pelo Consenso de Washington, que tiveram graves consequências para a economia brasileira.

Apesar de o Governo do Presidente Itamar Franco ter construído 26 novas escolas técnicas em pouco mais de dois anos, em 1994 foi aprovada pelo Congresso Nacional a Lei $n^{\circ} 8.948 / 94$, que determinava que a expansão da oferta de educação profissional, mediante a criação de novas unidades de ensino por parte da União, somente poderia ocorrer em parceria com Estados, Municípios, Distrito Federal, setor produtivo ou organizações não governamentais, que seriam responsáveis pela manutenção e gestão dos novos estabelecimentos de ensino.

O Governo do Presidente Fernando Henrique Cardoso construiu apenas 11 escolas técnicas federais entre os anos de 1995 a 2002. Outras 70 foram construídas com recursos do Banco Interamericano de Desenvolvimento. Mas a maioria delas estava fechada ao final de seu governo por falta de recursos para custeio.

Dentro do ideário neoliberal, foi realizada uma profunda reforma curricular na educação brasileira com o principal objetivo de alinhar as políticas e as ações das instituições ao cenário econômico, de acordo com as demandas locais e regionais. Em 1996, a Lei de Diretrizes e Bases da Educação Brasileira (LDBE) n ${ }^{\circ}$ 9.394 foi aprovada e no ano seguinte, por meio do Decreto 2208/1997, se deu a regulamentação de seus artigos 36, 39 e 42, que tratavam especificamente da educação profissional. O Decreto 2.208/1997 reforçou mais uma vez a dualidade estrutural da educação brasileira, criando matrizes curriculares e matrículas distintas para o estudante que desejava se formar técnico: uma no Ensino Médio e outra 
no Ensino Técnico, podendo ambos ocorrer em épocas ou instituições de ensino diferentes (BRASIL, 1997).

O Governo do Presidente Luís Inácio Lula da Silva procurou retomar o projeto nacional desenvolvimentista, inaugurado pelo Presidente Getúlio Vargas, com a ampliação de investimentos em grandes obras públicas, políticas de expansão do crédito e programas de transferência de renda, que tiveram como resultados o aumento real do salário-mínimo, a ampliação do PIB e a geração de 10,8 milhões de empregos entre os anos 2003 e 2010.

A queda no nível de desemprego, de 11,2\% em 2002 para 6,1\% em 2010, foi acompanhada pela pressão de empregadores e da classe política junto ao Governo Federal para ampliação das vagas em cursos profissionalizantes. Em discurso proferido no Senado Federal, em junho de 2003, o senador Paulo Renato Paim destacou que os novos postos de trabalho que estavam sendo criados estavam reservados para os trabalhadores que tivessem a capacidade de se adequar aos avanços tecnológicos e às exigências das empresas que agora enfrentam a competição em mercados globalizados.

A formação de trabalhadores capazes de enfrentar as mudanças econômicas e sociais que o mundo experimenta vai exigir que o País prossiga no necessário desenvolvimento da Educação Profissional, e para isso é imperativo que se inclua o ensino profissionalizante como prioridade na educação brasileira (PAIM, 2003).

Em 2005, a partir de uma ação integrada dos Dirigentes da RFEPCT, do MEC e da Frente Parlamentar em Defesa da Educação Profissional, houve a revogação do Decreto 2.208/1997 e teve início o maior projeto de construção de escolas profissionalizantes de toda a história brasileira. Esse processo foi integrado à Política Nacional de Desenvolvimento Nacional e com o Estudo da Dimensão Territorial para o Planejamento, que considerou a educação profissional como um dos meios para redução das desigualdades regionais e sociais brasileiras.

Do universo de mais de 55 milhões de jovens matriculados na educação básica no ano de 2005, menos de $2 \%$ cursavam o ensino técnico (INEP, 2005).

Desde 2005, quando foi realizado o lançamento do programa de expansão da RFEPCT, foram construídos mais de 400 novos campi em todo o país, que se somaram aos 152 já existentes. Na Figura 2 tem-se a evolução do número de câmpus 
da RFEPCT nas macrorregiões brasileiras. A região Sul teve um aumento de 318\% do número de câmpus. A região Sudeste cresceu 293\%, e a região Centro-Oeste teve a maior expansão: $600 \%$. A região Nordeste teve uma expansão de $252 \%$ e a região Norte de 300\%.

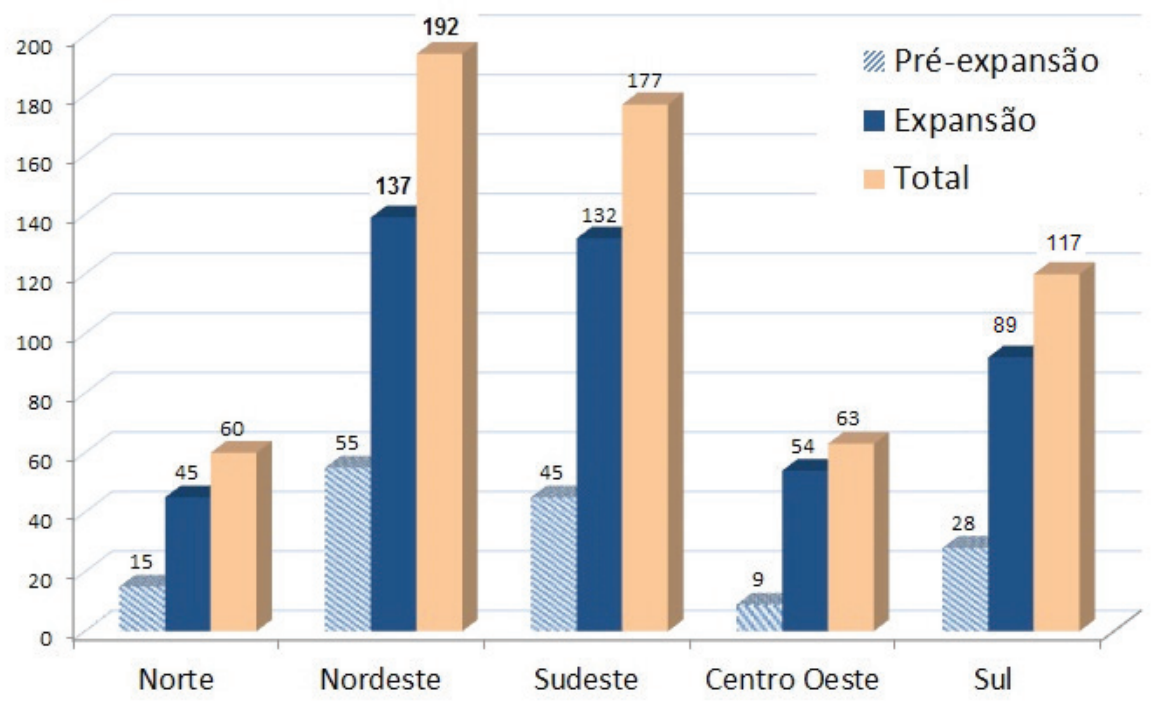

Figura 2. Evolução da distribuição dos campi da RFEPCT por macrorregião. Elaborado pelo autor a partir de dados do MEC (2015).

Além da expansão, a RFEPCT passou por uma importante reestruturação no ano de 2008. Por meio da Lei ${ }^{\circ} 11.892 / 2008$ (BRASIL, 2008), as Escolas Técnicas Federais, Escolas Agrotécnicas Federais e a maioria dos CEFETs foram agrupados para a criação de 38 Institutos Federais de Educação, Ciência e Tecnologia. A alteração teve início a partir do Decreto $n^{0} 6.905$ (24 de abril de 2007) e da Chamada Pública 02 (12 dezembro de 2007), que possibilitaram que as instituições da RFEPCT aderissem voluntariamente à transformação em IFETs ${ }^{4}$.

No Quadro 1 têm-se as diferentes denominações recebidas pela RFEPCT ao longo do tempo.

4 IFET era a sigla utilizada inicialmente pelo MEC para tratar os Institutos Federais de Educação, Ciência e Tecnologia. Atualmente é utilizada a sigla IFs. 
Quadro 1. Diferentes denominações das escolas da RFEPCT ao longo do tempo 5

\begin{tabular}{|l|l|}
\hline Ano & Denominação \\
\hline 1909 & Escola de Aprendizes Artífices \\
\hline 1937 & Liceus Profissionais \\
\hline 1942 & Escolas Industriais e Técnicas \\
\hline 1959 & Escolas Técnicas / Escolas Agrotécnicas Federais ${ }^{1}$ \\
\hline 1978 & Centros Federais de Educação Tecnológica \\
\hline 2008 & Institutos Federais de Educação, Ciência e Tecnologia \\
\hline
\end{tabular}

Fonte: Elaboração própria a partir do MEC (2015).

O novo modelo, diferente do concebido para a UTFPR, trouxe diversas preocupações para a RFEPCT. Segundo Otranto (2010), as Escolas Agrotécnicas Federais temiam pela perda de autonomia e de identidade, caso viessem a se integrar aos CEFETs para constituição dos Institutos Federais. Apesar da tentativa de se integrar todas as estruturas a RFEPCT continuou mantendo sua diversidade, conforme ilustrado na Figura 3, uma vez que os Institutos Federais coexistem com dois CEFETs, uma UTFPR, o Colégio Pedro II e 22 escolas técnicas vinculadas.
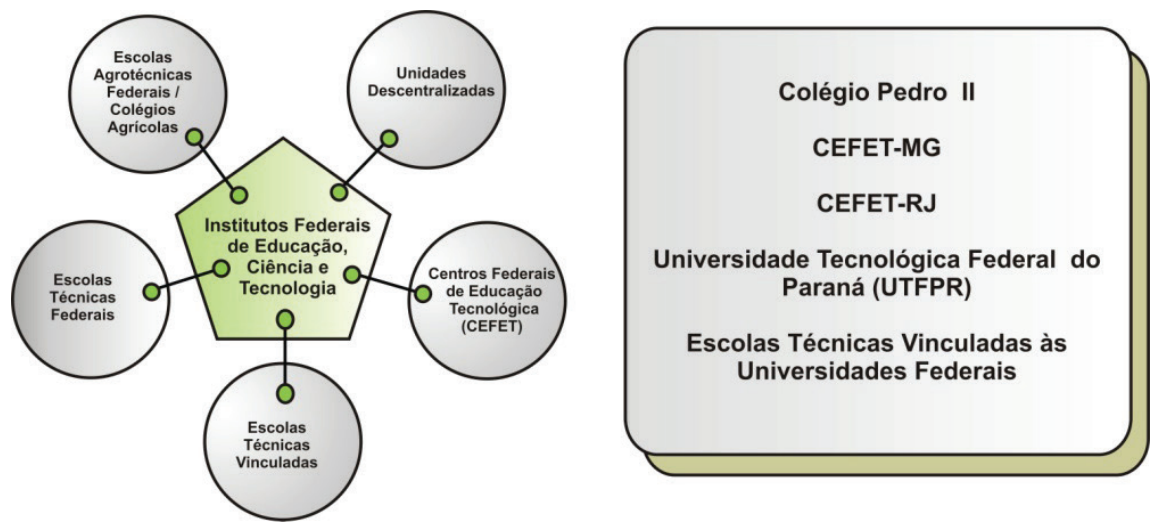

Figura 3. Nova estruturação da RFEPCT após a Lei dos Institutos Federais. Fonte: Elaboração própria a partir de dados do MEC (2015).

5 Disponível em: http://portal.mec.gov.br/setec/arquivos/centenario/historico_educacao_profissional.pdf 
Superados os obstáculos iniciais, os Institutos Federais foram instalados por meio da Lei $\mathrm{n}^{0} 11.892 / 2008$ e vêm assumindo uma nova institucionalidade. Há o compromisso legal de garantir a oferta de $50 \%$ de vagas para cursos técnicos e ofertar no mínimo $20 \%$ de vagas para cursos de formação de professores (BRASIL, 2008). Também tem entre suas finalidades o compromisso de atuar por meio de seus cursos, da pesquisa e da extensão, com objetivo de contribuir para o desenvolvimento regional. Segundo o MEC (2008), os Institutos Federais são instituições que articulam a educação superior, básica e profissional, pluricurricular e multicampi, especializadas na oferta de educação profissional e tecnológica em diferentes níveis e modalidades de ensino.

Uma vez que a RFEPCT tem sido apresentada nos documentos oficiais do MEC como responsável por contribuir para a redução das desigualdades regionais tem-se como objetivo do presente artigo mostrar como ocorreu o processo de espacialização da expansão da RFEPCT no Paraná e de que diferentes formas houve ampliação do Percentual de População Atendida e do Grau de Interiorização. O recorte temporal será entre os anos de 2005 a 2015.

Além da construção dos novos campi o MEC criou diversos outros programas como o Brasil Profissionalizado e o E-Tec Brasil. Por meio do Brasil Profissionalizado as redes de educação profissional e tecnológica dos Estados e do Distrito Federal puderam ampliar o número de escolas técnicas estaduais e o número de matrículas em cursos técnicos integrados ao ensino médio. A criação da Rede E-Tec Brasil teve $\mathrm{o}$ intuito de fomentar e induzir a oferta de educação profissional e tecnológica à distância, tanto para contribuir com o processo de interiorização da oferta de EPT, quanto para atender estudantes que não podem ou não desejam realizar cursos presenciais.

Na Figura 4 tem-se a espacialização dos municípios brasileiros atendidos pela RFEPCT, considerando-se os campi da pré-expansão e da expansão. Em alguns municípios, como Jaraguá do Sul, Curitiba, Rio de Janeiro entre outros, há mais de um câmpus instalado. Mas para efeitos de clareza de visualização houve apenas uma indicação no mapa. Apesar do forte processo de interiorização ainda é visível áreas onde há maior adensamento do número de câmpus e outras onde a RFEPCT ainda não se faz presente. 


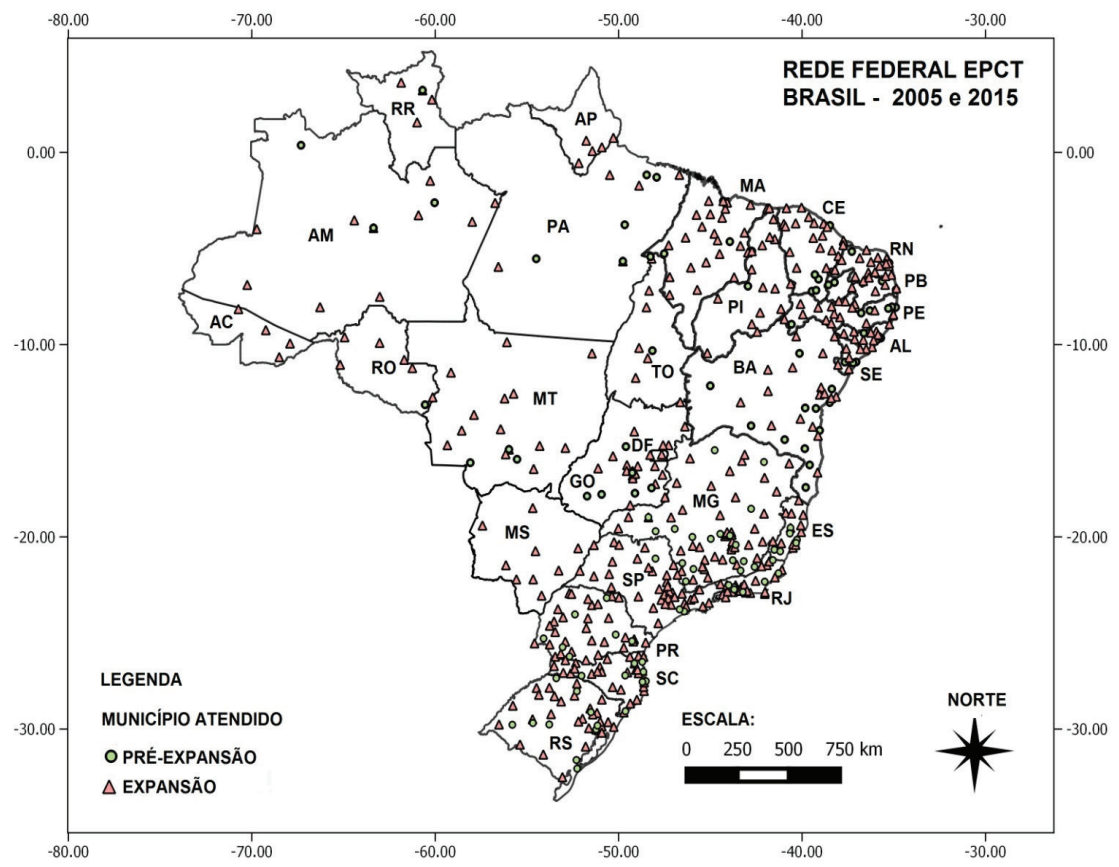

Figura 4 - Espacialização dos campi da RFEPCT após a expansão.

Fonte: Elaboração própria a partir dos dados do MEC (2015).

A região Sul do Brasil passou de 25 unidades em 2005 para 117 campi no ano de 2015. A seguir será mostrado como ocorreu a espacialização da RFEPCT no Estado do Paraná.

\section{A EXPANSÃO DA RFEPCT NO ESTADO DO PARANÁ}

Em 2005 a RFEPCT era composta pela UTFPR e por uma Escola Técnica Federal vinculada à Universidade Federal do Paraná localizada em Curitiba. 
Quadro 2. Distribuição da RFEPCT - Paraná

\begin{tabular}{|c|c|c|c|c|}
\hline \multirow{2}{*}{$\begin{array}{c}\text { Atual } \\
\text { Instituição }\end{array}$} & $\begin{array}{c}|c| \\
\text { Autarquias / Uneds (Unidades } \\
\text { Descentralizadas) }\end{array}$ & Municípios atendidos & $\begin{array}{c}\text { Sede da } \\
\text { Reitoria }\end{array}$ & $\begin{array}{c}\text { Número } \\
\text { de campi } \\
\text { em 2015 }\end{array}$ \\
\cline { 2 - 5 } IFPR & Antiga escola vinculada à UFPR & Curitiba & Curitiba & 25 \\
\hline UTFPR & $\begin{array}{c}\text { CEFET-PR - Curitiba e Uneds } \\
\text { Pato Branco, Dois Vizinhos, } \\
\text { Medianeira, Campo Mourão, } \\
\text { Cornélio Procópio, Ponta } \\
\text { Grossa }\end{array}$ & $\begin{array}{c}\text { Curitiba, Pato Branco, } \\
\text { Dois Vizinhos, } \\
\text { Medianeira, Campo } \\
\text { Mourão, Cornélio } \\
\text { Procópio, Ponta } \\
\text { Grossa }\end{array}$ & Curitiba & 12 \\
\hline
\end{tabular}

Fonte: Elaboração própria a partir de Relatórios do MEC (2008 e 2015).

A UTFPR, criada a partir do CEFET-PR por meio da Lei ${ }^{0} 11.184 / 2005$ (BRASIL, 2005), atendia os municípios de Curitiba, Campo Mourão, Pato Branco, Medianeira, Cornélio Procópio, Ponta Grossa e Dois Vizinhos. Sua origem remonta ao ano de 1909, quando foram criadas as 19 Escolas de Aprendizes Artífices. A Escola Técnica da Universidade Federal do Paraná (ET-UFPR), que deu origem ao Instituto Federal do Paraná, tem origem na antiga Escola Alemã e no Colégio Progresso (HELLMANN 6,2014$)$.

Até 2005 não havia uma distribuição espacial equilibrada da oferta de educação profissional e tecnológica no Estado do Paraná. As mesorregiões Noroeste Paranaense, Norte-Central Paranaense, Centro-Sul Paranaense e Sudeste do Paraná não eram atendidas. A UTFPR cresceu de 07 para 12 campi entre os anos de 2005 e 2015. Na Fase 1 da expansão, a UTFPR foi contemplada com os campi Londrina, Apucarana, Toledo e Francisco Beltrão. Na Fase 2 a instituição não recebeu nenhum novo câmpus. Na Fase 3 a UTFPR recebeu o câmpus de Guarapuava. O IFPR, que surgiu em 2008 a partir da Lei $\mathrm{n}^{0}$ 11.892/2008, passou de apenas um câmpus (Curitiba) para 25 campi localizados nos municípios de Curitiba, Jacarezinho, Paranavaí, Umuarama, Telêmaco Borba, Foz do Iguaçu, Paranaguá, Astorga, Ivaiporã, Goioerê, Pitanga, Assis Chateaubriand, Capanema, Cascavel, Quedas do Iguaçu, Jaguariaíva, Campo Largo, Colombo, Pinhais, União da Vitória, Barracão, Londrina,

Disponível em: http://reitoria.ifpr.edu.br/wp-content/uploads/2013/12/Artigo-Completo-Observatorio-Regional.pdf 
Palmas e Irati. Na Figura 5 tem-se a representação da RFEPCT na pré-expansão e após a expansão (2015).

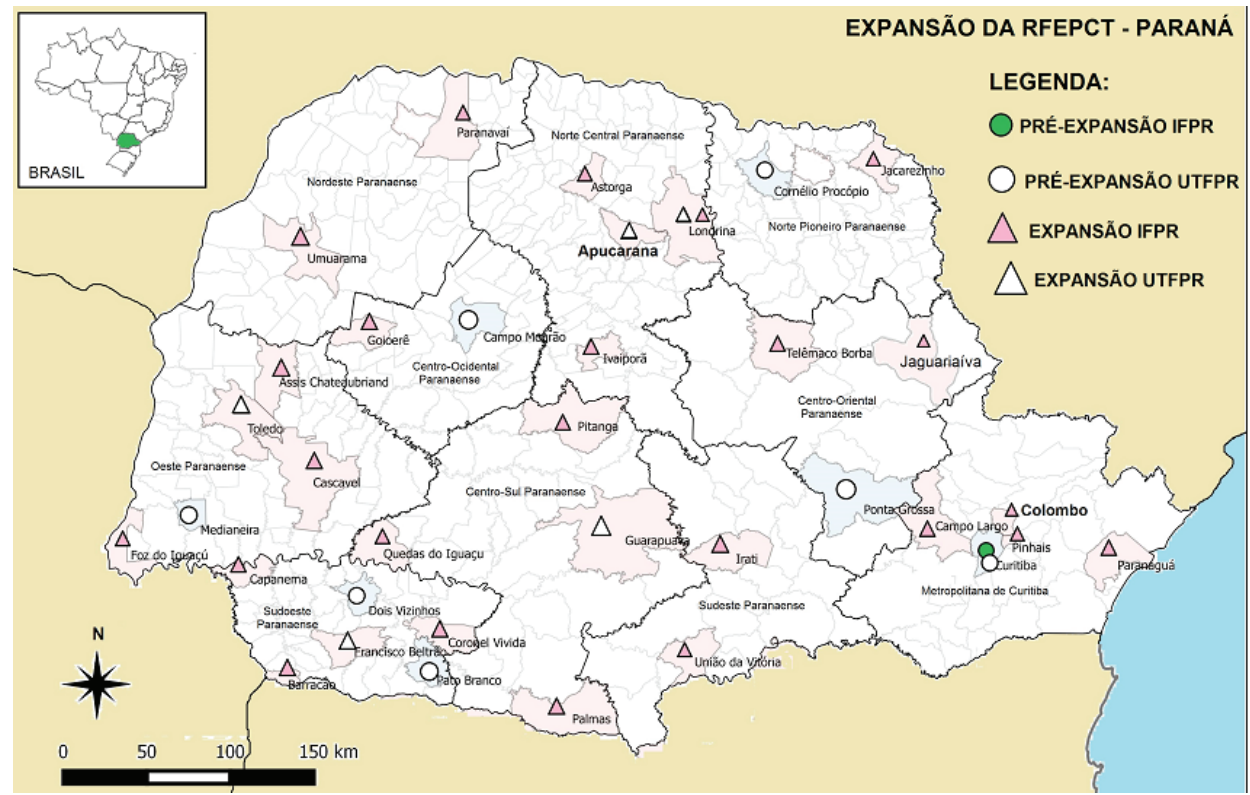

Figura 5. Espacialização da RFEPCT no Paraná após a expansão.

Fonte: Elaboração própria a partir de dados do MEC (2015).

O reduzido número de escolas da RFEPCT fazia com que os estudantes tivessem que percorrer longas distâncias para acessar os cursos. É razoável admitir a hipótese de que quanto mais interiorizada é a oferta de matrículas da RFEPCT, mais acessíveis os cursos profissionalizantes se tornam para a população. Para avaliar esse grau de acessibilidade dos cursos da RFEPCT - Paraná, propôs-se o cálculo do Grau de Interiorização (GRINT). O indicador é mais próximo de 1 quanto mais distante o câmpus se encontrar da capital. Na equação representada a seguir "n" representa o número de câmpus, "d1, d2...dn" representam as distâncias parciais em relação à Reitoria e "dmax" representa a distância do município mais distante da capital. No caso do Paraná, "dmax" é de 585km que é a distância entre Foz do Iguaçu e Curitiba.

$$
G R I N T=\frac{1}{n} \times\left(\frac{d 1}{d \max }+\frac{d 2}{d \max }+\ldots . .+\frac{d}{d \max }\right)
$$


O GRINT do Estado do Paraná na pré-expansão era de 0,46. Após a expansão o GRINT do Paraná passou para 0,52.

Para se calcular o percentual de aumento da população potencialmente atendida pela RFEPCT calculou-se o Índice de População Potencialmente Atendida (IPPA) dividindo-se a população dos municípios atendidos pela RFEPCT pela população total da região:

$$
\text { IPPA }=\frac{\sum \text { População potencialmente atendida }}{\text { População total da região }}
$$

No final de 2015, o Índice de População Potencialmente Atendida (IPPA) era da ordem de 50\% no Paraná. Esse Índice era de apenas 23\% em 20057. Atualmente, mesmo chegando a quase 40 campi instalados, o Estado do Paraná é o que tem o menor IPPA da região Sul. Na Figura 6 tem-se a representação gráfica da população potencialmente atendida nos municípios contemplados pela RFEPCT-Paraná.

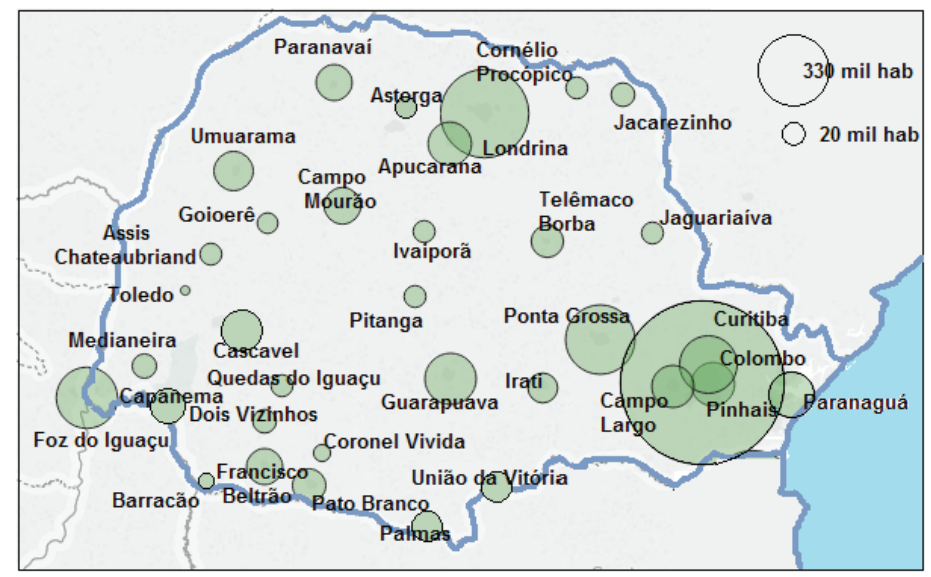

Figura 6. Representação da população atendida pelos campi da RFEPCT. Fonte: Elaboração própria por meio do software Tableau Public e IBGE (2015).

Dos seis municípios atendidos em 2005 apenas dois deles possuíam menos de 40 mil habitantes. Em 2015 a RFEPCT-Paraná era composta por 11 campi localizados em municípios com menos de 40 mil habitantes, 13 campi em municípios

\footnotetext{
A população aproximada do Estado do Paraná no ano de 2005 era de 9,9 milhões de pessoas.
} 
com população entre 40 mil e 100 mil habitantes (Quadro 3).

Quadro 3. Distribuição da população dos municípios atendidos pela RFEPCT

\begin{tabular}{|c|c|}
\hline $\begin{array}{c}\text { Faixa de } \\
\text { população } \\
\text { (habitantes) }\end{array}$ & Municípios atendidos \\
\hline Até 40 mil & $\begin{array}{c}\text { Toledo, Barracão, Coronel Vivida, Astorga, Goioerê, Pitanga, Ivaiporãa } \\
\text { Quedas do Iguaçu, Assis Chateaubriand, Dois Vizinhos, Jaguariaíva e } \\
\text { Medianeira }\end{array}$ \\
\hline $\begin{array}{c}\text { De } 40 \text { mil a } 100 \\
\text { mil }\end{array}$ & $\begin{array}{c}\text { Jacarezinho, Cornélio Procópio, Palmas, União da Vitória, Irati, Capanema, } \\
\text { Pato Branco, Cascavel, Telêmaco Borba, Campo Mourão, Francisco Beltrão e } \\
\text { Paranavaí. }\end{array}$ \\
\hline Mais de 100 mil & $\begin{array}{c}\text { Umuarama, Campo Largo, Pinhais, Apucarana, Paranaguá, Guarapuava, } \\
\text { Colombo, Foz do Iguaçu, Ponta Grossa, Londrina (2x) e Curitiba (2x). }\end{array}$ \\
\hline
\end{tabular}

Fonte: Elaboração própria a partir de dados do IBGE (2015).

O número de empregos formais e a distribuição percentual da população e de matrículas ofertadas pela RFEPCT por mesorregião do Paraná são mostrados na Figura 7.

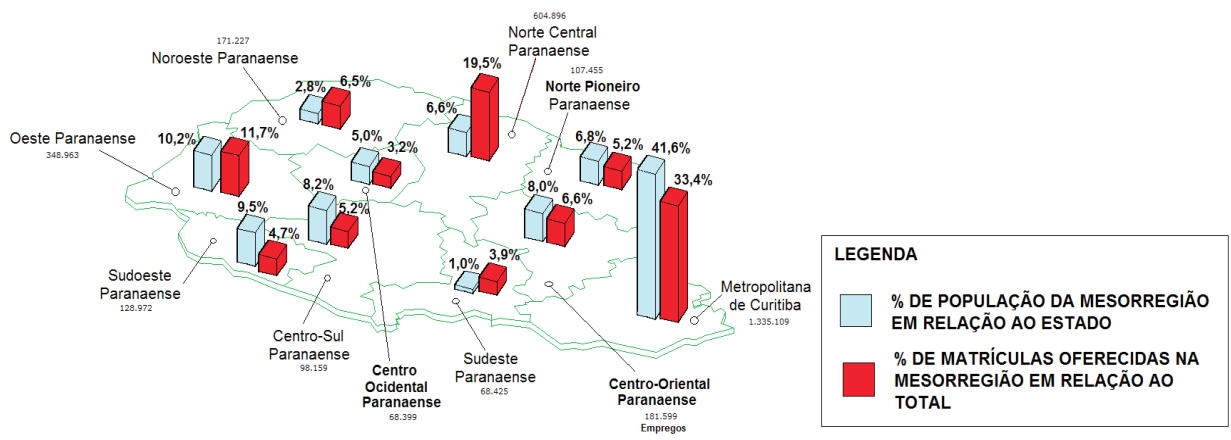

Figura 7. Distribuição da população e das matrículas da RFEPCT no Paraná.

Elaboração própria a partir dos dados do MEC (2015), RAIS (2015) e IBGE (2015).

$\mathrm{Na}$ maioria das mesorregiões paranaenses tem-se um déficit percentual de matrículas em relação ao percentual da população.

Segundo Thomaz (2013), nos últimos anos tem havido a ampliação do 
percentual de estudantes de menor renda na RFEPCT. O PSC ${ }^{8}$ - perfil socioeconômico de clientela - que mede o nível de renda dos estudantes da RFEPCT, calculado entre os anos 2007 a 2011, mostrou que metade dos estudantes matriculados recebia até 1,18 salário-mínimo mensal per capita. Em 2007, metade deles recebia até 1,68 salário-mínimo per capita. Mas a inclusão dos estudantes provenientes das famílias com menor rendimento per capita vem acontecendo em diferentes proporções em todo o país. A maioria dos estudantes do IFPR possui renda familiar média per capita mensal menor que 1 salário mínimo (53\%).

Conforme mostrado na Figura 8, as três mesorregiões com menor PIB per capita do Paraná são Norte-Pioneiro (NP), Sudeste Paranaense (SE) e Noroeste Paranaense (NO). Nessas mesorregiões estão instalados os campi Jacarezinho, Cornélio Procópio; Irati e União da Vitória; Umuarama e Paranavaí respectivamente.
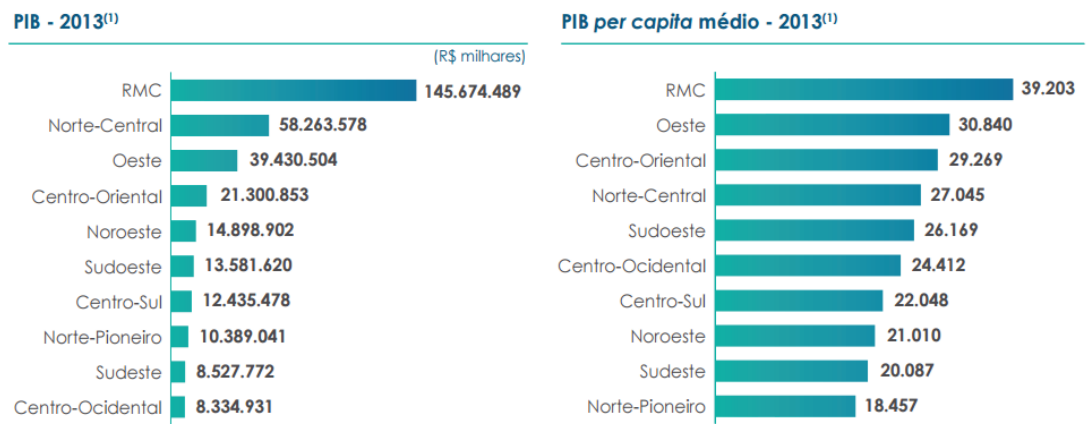

Figura 8. Distribuição do PIB per capita das mesorregiões paranaenses.

Fonte: Paraná em números (FIEP, 2015).

No Paraná foram identificados pelo Governo Federal quatro Territórios da Cidadania9 ${ }^{9}$. São eles: Cantuquiriguaçu, Norte Pioneiro, Paraná Centro e Vale do Ribeira, conforme ilustrado na Figura 9. Ao todo vivem nesses quatro territórios aproximadamente 1 milhão de habitantes.

\footnotetext{
8 PSC é um indicador previsto no Acórdão do TCU para avaliação da Rede Federal EPCT e que mede a condição socioeconômica dos estudantes.

9 O Programa "Territórios da Cidadania" foi criado em 2008 pelo Governo Federal com o objetivo de promover o desenvolvimento econômico e universalizar programas básicos de cidadania por meio de uma estratégia de desenvolvimento territorial sustentável coordenando ações de diversos ministérios, Estados e municípios de forma articulada, conforme informações disponíveis em: < http://www.mda.gov.br/sitemda/sites/sitemda/ files/ceazinepdf/3638134.pdf $>$.
} 


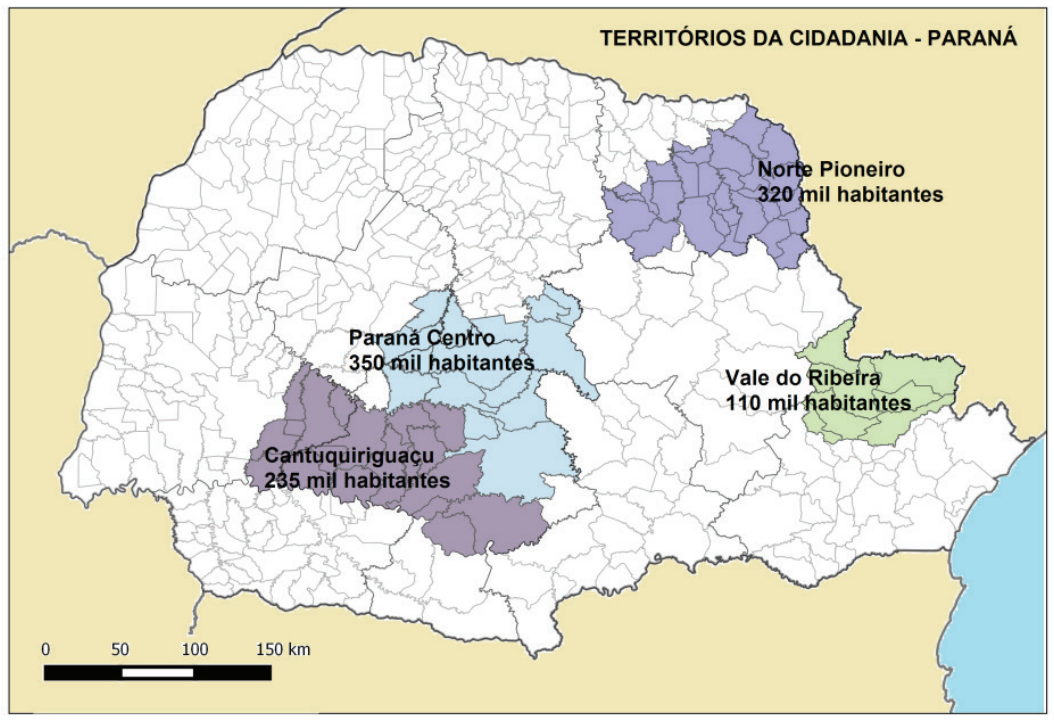

Figura 9. Territórios da Cidadania identificados na região Sul do Brasil. Fonte: Elaboração própria a partir de BRASIL (2008).

No Território Cantuquiriguaçu tem-se o câmpus Quedas do Iguaçu. No Território Norte Pioneiro tem-se o câmpus Jacarezinho. No Território Paraná Centro tem-se os campi Guarapuava e Pitanga. Finalmente, no Território Vale do Ribeira nenhum câmpus foi instalado.

O IDHM médio dos municípios atendidos pela pré-expansão era de 0,727. A expansão atendeu municípios com IDHM médio de 0,702. De acordo com o Atlas (2010), as três mesorregiões do Paraná com menores índices IDHM são Centro Oriental Paranaense (CO) com IDHM médio de 0,689, Centro-Sul Paranaense (CS) com IDHM médio de 0,654 e Sudeste Paranaense (SE) com IDHM médio de 0,679. Nessas mesorregiões estão instalados os campi Quedas do Iguaçu, Guarapuava, Pitanga, Palmas (CS); Irati e União da Vitória (SE); e Telêmaco Borba, Jaguariaíva e Ponta Grossa (CO).

Segundo Bosi (2000) a existência de uma universidade pública muitas vezes é suficiente para melhorar as condições de vida de um município. Devido ao conhecimento que produz e propaga por meio das pessoas que forma, ela colabora ativamente para o progresso material, a melhoria da qualidade de vida e o ambiente 
cultural em que está inserida. Uma universidade possibilita a movimentação financeira decorrente do pagamento de salários de professores e de funcionários, de investimentos em obras, equipamentos, custeio e gastos dos alunos oriundos de outros municípios. Esses efeitos são maiores nos municípios menores. Os Institutos Federais, equiparados às Universidades Federais, apresentam essas mesmas características. No Quadro 2 tem-se a distribuição da população dos municípios atendidos pela RFEPCT no Paraná.

A estimativa é que um câmpus tenha um custo médio de implantação da ordem de 14 milhões de reais somando-se os gastos nas obras e na aquisição de móveis e equipamentos para laboratórios. Os custos de manutenção (custeio) de um câmpus estão relacionados com o pagamento de servidores de limpeza, zeladoria, vigilância, motoristas, energia elétrica, água, telefone, papel, impressoras, material de consumo para laboratório entre outras despesas. O orçamento médio de custeio de um novo câmpus é de aproximadamente $\mathrm{R} \$ 1.500 .000,00$ ao ano. Ao longo de 20 anos têm-se 30 milhões de reais potencialmente empregados na economia dos municípios. Além disso, considerando-se um quadro de 50 docentes e 40 TAEs em média por campus, com salários da ordem de $\mathrm{R} \$ 7.000,00$ e $\mathrm{R} \$$ $3.500,00$ respectivamente, tem-se um valor repassado pelo Governo Federal para os servidores da ordem de $\mathrm{R} \$ 6$ milhões ao ano. Ao longo de 20 anos tem-se um repasse de, aproximadamente, 120 milhões de reais na forma de salários. De acordo com dados do ingresso do IFPR e da UTFPR, aproximadamente, $15 \%$ dos estudantes de um câmpus são oriundos de outros municípios. Considerando-se uma média de aproximadamente 1.200 matrículas em cada câmpus, têm-se aproximadamente 180 alunos nessa condição por câmpus. Se estimarmos um gasto médio por estudante de meio salário mínimo mensal, tem-se ao longo de doze meses quase $\mathrm{R} \$ 1$ milhão.

A movimentação de recursos financeiros aumenta à medida que novos cursos e novas vagas são criados pelos campi, exercendo um efeito dinâmico e multiplicador sobre as atividades econômicas locais. Para efeitos de comparação foi escolhida uma amostra não aleatória, mas representativa de cinco campi, para avaliação da comparação entre a Receita dos Municípios e a movimentação financeira decorrente dos salários dos servidores docentes e TAEs, dos custos de manutenção e dos gastos dos estudantes que vêm de outros municípios (Tabela 1). 
Tabela 1. Movimentação financeira dos novos campi e as transferências constitucionais

\begin{tabular}{c|c|c|c}
\hline Câmpus/município & $\begin{array}{c}\text { População } \\
\text { estimada em } \\
2016 \text { (IBGE) }\end{array}$ & $\begin{array}{c}\text { Estimativa média dos recursos } \\
\text { anuais decorrentes dos gastos } \\
\text { dos alunos externos, dos } \\
\text { salários dos servidores e do } \\
\text { custeio de cada câmpus (R\$) }\end{array}$ & $\begin{array}{c}\text { Transferências } \\
\text { constitucionais para } \\
\text { o município }{ }^{2} \text { (R\$) }\end{array}$ \\
\hline Ivaiporã & 32.715 & $8.500 .000,00$ & 18,07 milhões \\
\hline Jacarezinho & 40.253 & $8.500 .000,00$ & 21,8 milhões \\
\hline Irati & 60.070 & $8.500 .000,00$ & 25,9 milhões \\
\hline Paranavaí & 87.316 & $8.500 .000,00$ & 35,0 milhões \\
\hline Guarapuava & 179.256 & $8.500 .000,00$ & 65,7 milhões \\
\hline
\end{tabular}

Fonte: Elaboração própria a partir do Portal da Transparência (BRASIL, 2017).

Como é possível visualizar na Tabela 1, a movimentação financeira decorrente dos gastos dos alunos externos, dos salários dos servidores e do custeio de cada câmpus é relevante se comparada com as transferências constitucionais do Governo Federal, principalmente nos municípios menores.

\section{CONCLUSÕES}

O processo de expansão da Rede Federal EPCT, que teve início no ano de 2005, foi analisado a partir dos indicadores socioeconômicos dos aproximadamente 550 municípios brasileiros onde há campi instalados. Procurou-se confrontar esses dados com os critérios oficiais divulgados pelo MEC para definição das localidades atendidas pela recente expansão da RFEPCT. Além de atender inicialmente as regiões não atendidas, contemplar os Arranjos Produtivos Locais e os municípios localizados nos Territórios da Cidadania e no G-100, a redução das desigualdades regionais foi uma das motivações apontadas pelo MEC. Em termos quantitativos, comprovou-se por meio do cálculo do Grau de Interiorização que a expansão da RFEPCT proporcionou uma interiorização das matrículas na educação profissional e tecnológica, com atendimento prioritariamente das regiões mais pobres do país. Houve também uma ampliação do Percentual de População Atendida e do percentual de câmpus em cidades com até 40 mil habitantes. A partir da análise dos 
dados; também é possível inferir que a expansão atendeu as cidades mais dinâmicas em termos de crescimento populacional e com os menores IDH-M. No entanto, considerando-se que muitos campi ainda estão em fase final de implantação, é muito cedo para se avaliar quantitativamente seus reais impactos no desenvolvimento regional.

\section{REFERÊNCIAS}

ATLAS DO DESENVOLVIMENTO HUMANO MUNICIPAL. Atlas do Desenvolvimento Humano no Brasil. 2010. Disponível em: < http://www.atlasbrasil.org.br/2013>. Acesso em: 01 maio 2017.

BOSI, A. A presença da Universidade Pública. Instituto de Estudos Avançados da Universidade de São Paulo (IEA-USP). [s.l.; s.n.]: 2000.

BRASIL. Decreto n ${ }^{0}$ 7.566, de 23 de setembro de 1909. Cria nas capitais dos Estados das Escolas de Aprendizes Artífices, para o ensino profissional primário e gratuito. Disponível em: < portal.mec.gov.br/setec/arquivos/pdf3/decreto_7566_1909.pdf > . Acesso em: 10 abr. 2016.

BRASIL. Lei $n^{\mathbf{0}}$ 11.184/2005. Dispõe sobre a transformação do Centro Federal de Educação Tecnológica do Paraná em Universidade Tecnológica Federal do Paraná e dá outras providências. Disponível em: < http://www.planalto.gov.br/ccivil_03/_ Ato2004-2006/2005/Lei/L11184.htm> . Acesso em: 10 abr. 2016.

BRASIL. Lei $n^{0}$ 11.892, de 29 de dezembro de 2008. Institui a Rede Federal de Educação Profissional, Científica e Tecnológica, cria os Institutos Federais de Educação, Ciência e Tecnologia, e dá outras providências. Disponível em: <www. planalto.gov.br/ccivil_03/_ato2007.../2008/lei/111892.htm>. Acesso em: 18 ago. 2014.

BRASIL. Lei no 8.948/94, de 8 de dezembro de 1994. Dispõe sobre a instituição do Sistema Nacional de Educação Tecnológica e dá outras providências. Disponível em: <http://www.planalto.gov.br/Ccivil_03/Leis/L8948.htm\&gt>. Acesso em: 24 set. 2015. 
BRASIL. Lei de Diretrizes e Bases da Educação Nacional - LDB 9.394, de 20 de dezembro de 1996. Brasília: Ministério da Educação. 1996. Disponível em: < http:// www.planalto.gov.br/ccivil_03/leis/L9394.htm\&gt>. Acesso em: 24 jun. 2015.

BRASIL. Decreto $\mathrm{n}^{\circ} 2208$, de 17 de abril de 1997. Regulamenta o art. 36 e os artigos 39 a 42 da Lei no 9394/96. Diário Oficial da União, Brasília de 18/04/1997, seção 1, p. 7760 .

BRASIL. Territórios da Cidadania. Brasília. 2008. Disponível em: <http://www. mda.gov.br/sitemda/sites/sitemda/files/ceazinepdf/3638408.pdf $>$. Acesso em: 20 de maio 2017.

BRASIL. Portal da Transparência. Brasília: [s.n.], 2017.

FIEP - Federação das Indústrias do Paraná. Paraná em números. Curitiba: Fiep, 2016.

INSTITUTO BRASILEIRO DE GEOGRAFIA E ESTATÍSTICA - IBGE. Diretoria de Pesquisas - DPE. Coordenação de População e Indicadores Sociais - COPIS. Estimativas da população residente no Brasil e Unidades da Federação com data de referência em $1^{\circ}$ de julho de 2014. Brasília, 2014.

IBGE. Censo Demográfico. Rio de Janeiro: IBGE, 2010.

INSTITUTO NACIONAL DE ESTUDOS E PESQUISAS EDUCACIONAIS ANÍSIO TEIXEIRA - INEP. Censo Escolar. Brasília. 2005.

MINISTÉRIO DA EDUCAÇÃO - MEC. Concepções e Diretrizes dos Institutos Federais. Brasília: MEC, 2008.

MINISTÉRIO DA EDUCAÇÃO - MEC. Sinopse das ações do Ministério da Educação. Brasília: MEC, 2011.

MINISTÉRIO DA EDUCAÇÃO - MEC. Relatório Anual de Análise dos Indicadores de Gestão das Instituições Federais de Educação Profissional, Científica e Tecnológica. Brasília: MEC, 2015. 
MINISTÉRIO DA EDUCAÇÃO - MEC. Expansão da Rede Federal. Disponível em: $<$ http://redefederal.mec.gov.br/expansaodaredefederal > Acesso em: 28 jun. 2015.

OTRANTO, C.R. Criação e implantação dos Institutos Federais de Educação, ciência e tecnologia - IFETs. 2010. Disponível em: < http://www.celia.na-web.net/ pasta1/trabalho19.htm\&gt > Acesso em: 15 jul. 2015.

PAIM, P. R. Pronunciamento em que defende a necessidade de fortalecimento do Programa de Expansão da Educação Profissional Proep/MEC. 2003. Disponível em: <http://www.senadorpaim.com.br/verDiscurso.php?id=1057>. Acesso em: 15 jul. 2015.

RAIS. Relação Anual de Informações Sociais: anuário RAIS. 2015. Disponível em: $<$ http:/bi.mte.gov.br/bgcaged/caged_anuario_rais/anuario.htm $>$. Acesso em: jul. 2016.

SANTOS, M. A Natureza do Espaço: técnica e tempo, razão e emoção. 4. ed. São Paulo: Ed. da USP, 2012.

SILVA, J. G. A Expansão da Rede Federal de Educação Profissional, Científica e Tecnológica entre os anos 2005 e 2015 e suas implicações socioespaciais no Estado de Santa Catarina. 2017. Tese (Doutorado) - UFSC, Florianópolis, 2017.

THOMAZ, S. M. Avaliação do impacto da expansão da rede federal na qualidade dos Institutos Federais de Educação segundo indicadores de desempenho. 2013. Dissertação (Mestrado) - Universidade Federal do Rio Grande do Norte, Natal, 2013.

Recebido em: 19/06/2017 Aceito em:20/03/2018 